\title{
In situ X-ray measurements over large Q-space to study the evolution of oxide thin films prepared by RF sputter deposition
}

\author{
P. Walter ${ }^{1,2, *}$ (1), J. Wernecke ${ }^{1}$, M. Scholz ${ }^{1}$, D. Reuther ${ }^{1}$, A. Rothkirch ${ }^{1}$, D. Haas ${ }^{1}$, \\ J. Blume ${ }^{1}$, A. Resta ${ }^{3}$, A. Vlad ${ }^{3}$, O. Faley ${ }^{4}$, S. Schipmann ${ }^{4}$, A. Nent ${ }^{4}$, O. Seeck ${ }^{1}$, \\ A.-C. Dippel ${ }^{1}$, and U. Klemradt ${ }^{4}$ \\ ${ }^{1}$ Deutsches Elektronen-Synchrotron, Notkestr. 85, 22607 Hamburg, Germany \\ ${ }^{2}$ SLAC National Accelerator Laboratory, 2575 Sand Hill Road, Menlo Park, CA 94025, USA \\ ${ }^{3}$ Synchrotron SOLEIL, L'Orme des Merisiers, Saint-Aubin, Boîte Postale 48, 91192 Gif sur Yvette Cedex, France \\ ${ }^{4}$ 2nd. Institute of Physics B and JARA-FIT, RWTH Aachen University, Otto-Blumenthal-Str. 1, 52074 Aachen, Germany
}

Received: 12 July 2020

Accepted: 11 September 2020

(C) This is a U.S. government work and its text is not subject to copyright protection in the United States; however, its text may be subject to foreign copyright protection 2020

\begin{abstract}
Sputter deposition is a versatile and industrially important deposition technique for thin films, with increasing demand for matching the characteristics of thin film materials to specific requirements. The actual film properties are largely determined by sputtering parameters such as pressure conditions, temperature and power settings. By means of various X-ray diffraction and scattering techniques, it is shown that the characterization of film formation and growth is feasible in real time at synchrotron sources, thus adding an important dimension to the fundamental understanding of the evolution of thin film microstructure. In particular, grazing incidence small-angle $X$-ray scattering, grazing incidence X-ray powder diffraction and X-ray reflectometry are used in a complementary manner to study the influence of deposition temperature and substrate choice on the crystallization kinetics and growth of polycrystalline $\mathrm{BaTiO}_{3}$ films.
\end{abstract}

\section{Introduction}

The remarkable features of modern synchrotron radiation sources allow real-time studies of a variety of reactions, development or manufacturing processes. By studying a method during its application with a time resolution in the sub-second regime, direct conclusions of the various influences can be drawn. Due to its variety of parameters, plasma sputter deposition is a manufacturing process that is suitable for time-resolved, nondestructive measurements [1, 2]. For industry, sputter deposition is a manifold and important manufacturing technique for

Handling Editor: M. Grant Norton.

Address correspondence to E-mail: pwalter@slac.stanford.edu 
thin films. Therefore, the need for the adaption of the properties of thin film materials is increasing for a wide range of requirements. The parameters that determine the film properties during sputter deposition are, e.g., pressure conditions, power setting and also substrate material and temperature [3-6]. Depending on the particular application of the layers, the properties of the thin film should be adapted in order to achieve optimum performance. It is well established that the macroscopic properties are inherently correlated with the microstructure and crystallographic state of the thin film. However, the general understanding of the underlying physical and crystallographic mechanism is yet mostly based on ex situ measurement after the preparation. Hence, as part of the miniaturization of microelectronic circuits and devices and the necessary adaptation of the film thickness as well as the grain size, etc., the deposition process should be examined in real time during the deposition. For this purpose, a sputter deposition chamber was built to investigate the deposition process in real time using intense X-rays from different synchrotron radiation sources (see Fig. 1) [7].

This article addresses state-of-the-art sputtering experiment aiming for in situ investigation of properties of oxide materials as well as their interaction with the substrate. Oxide thin films find use in a wide range of applications [8]. One such example is barium titanate $\left(\mathrm{BaTiO}_{3}\right)$, which can be considered the classic perovskite ferroelectric material from a historical point of view. It was the first material of this type in which the B site cation displacement was discovered to be the origin of ferroelectricity [9-11]. More known features are ferroelectric behavior at room temperature, high dielectric constant as well as outstanding piezoelectric properties [12, 13]. $\mathrm{BaTiO}_{3}$ has been used in pure and chemically modified powder and epitaxial thin films as the functional component in various electrical applications for several decades [14]. Its chemical composition makes it an attractive material in today's strive for lead-free ferroelectrics [15]. Moreover, it was found under appropriate boundary conditions that even single unit cell high $\mathrm{BaTiO}_{3}$ layers show ferroelectric behavior [16, 17].

A better structural insight into the early interface formation is required to understand the early interface formation and most importantly to get a better understanding of the crystallization procedure for the future improvement of amorphous, epitaxial and polycrystalline thin films. This could only be achieved in situ with the advent of X-rays from a third-generation synchrotron. Figure 1 shows the principle of a scattering or diffraction measurement with our in situ sputtering chamber. For a detailed description of the chamber, see Ref. [7].

\section{Experimental details}

\section{Preparation procedures}

Oxide thin films and in the scope of this work $\mathrm{BaTiO}_{3}$ thin films usually are prepared by reactive sputter

Figure 1 Schematic setup for in situ sputter deposition measurements, with the X-ray beam (yellow), the chamber (silver) including the sample holder in grazing incidence geometry and a 2D detector (blue). Data taken with a certain time resolution and transferred to a PC.

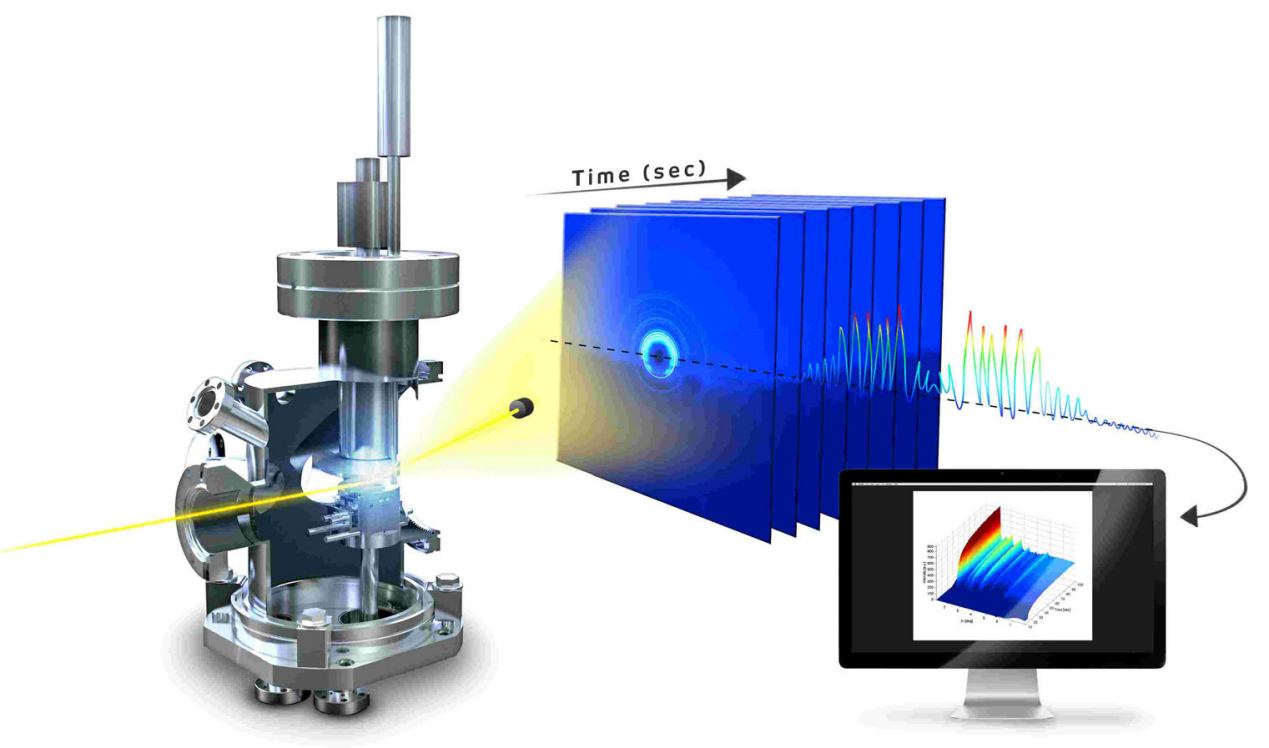


deposition. In most cases, sputter deposition uses a magnetically enhanced glow discharge or magnetron discharge to produce the ions which bombard and sputter the cathode material [18]. Therefore, the reactive gas and its amount compared to the main plasma gas are important. The choice of these parameters depends mostly on the desired thin film material as well as on the intended film application. Moreover, depending on the application, the crystallization is an important step. Multiple events of atomic rearrangement take place in the course of heat treatment.

There are three main preparation techniques for sputter deposition of oxide thin films:

- Deposition of a thin film to a certain thickness without heating the substrate and annealing the film at a later point in an oxygen atmosphere.

- Deposition of the material to the final thickness in the presence of an already heated substrate, where the substrate temperature can be as high as the annealing temperature of the thin film.

- Sequential deposition of the film in small steps to the final thickness while inducing the crystallization after every step of deposition.

In this work, we focused on the first two preparation procedures to prepare the thin films.

\section{Experimental techniques}

For thin film analysis, whether they are amorphous, polycrystalline or single crystalline, reciprocal space offers detailed structural information, which is particularly useful when combined with sub-second time resolution during growth processes. Because of that, this work is based on the following techniques [7]:

- In situ grazing incidence small-angle X-ray scattering (GISAXS) experiments allow for studies of the sputter deposition process already from the early stages of deposition [19, 20]. Therefore, GISAXS gives a deep understanding of the influence of process parameters on the grain size, shape, size distribution and correlation lengths. If heat treatment is needed to initiate crystallization, one can perform GISAXS before, during and after the crystallization.

- In situ grazing incidence X-ray powder diffraction (GIXRPD) provides information about phases or phase transitions, crystallinity, lattice parameters and can be used for crystal structure solution and refinement. In addition, in situ GIXRPD is the basis to derive the crystallization pathway and transformation kinetics during annealing of the deposited layers. In contrast to GISAXS, this method is sensitive to atomic distances.

- In situ X-ray reflectivity (XRR) measurements provide the film thickness, surface and interface roughness and electron density as well as their changes due to the crystallization process.

All these techniques provide the possibility to study many aspects of thin films in situ and thereby to analyze the dependency of the film development on the processing parameters.

To collect these information over a large Q-space including the information of small-angle scattering and diffraction, it usually demands two detectors: one with large sample-to-detector distance (SDD) for GISAXS, ideally a 2D detector, and one to detect the GIXRPD over a certain angle where Bragg reflexes are expected to emerge. For the diffraction, one can use a point or $2 \mathrm{D}$ detector. In order to obtain diffraction data, a 2D detector can provide in-plane information or can indicate preferred orientation [21]. The detection of XRR depends on the experimental setup and the installed detectors. It can be done with a 2D detector or with a point detector installed at an diffractometer arm (see "Measurements" section). The following sections are organized according to the combinations point detector $+2 \mathrm{D}$ detector and two $2 \mathrm{D}$ detectors.

\section{Measurements}

In the present work, $\mathrm{BaTiO}_{3}$ thin film evolution was studied at two different synchrotron beamlines dedicated to surface diffraction, i.e., SIXS at SOLEIL [22] and P08 at PETRA III [23]. At SIXS, a point detector installed at the diffractometer arm and a pixel hybrid 2D detector were used. At P08, two 2D detectors were used simultaneously.

If not mentioned otherwise, the measurements were performed with the following parameters. The plasma process and substrate heating were started $10 \mathrm{~min}$. before opening the shutter in front of the sputtering target. The sputtering power on the $\mathrm{BaTiO}_{3}$ target was $10 \mathrm{~W} / \mathrm{cm}^{2}$ at SOLEIL and 
$14 \mathrm{~W} / \mathrm{cm}^{2}$ at PETRA III, and the gas mixture was $80 \%$ argon (Ar) and $20 \%$ oxygen $\left(\mathrm{O}_{2}\right)$ with a total flow of 1 standard cubic centimeter per minute (SCCM). The distance between the sputtering target and substrate was fixed at a distance of $4 \mathrm{~cm}$. The films were deposited on pre-cleaned $\mathrm{Si}, \mathrm{SiO}_{2}$ or $\mathrm{MgO}$ wafers with a size of $10 \times 10 \mathrm{~mm}^{2}$.

\section{Measurements with a 2D and a point detector}

For the measurements at SIXS, the chamber was mounted on a heavy-duty hexapod without further weight compensation. According to the experimental setup, the beamline energy was chosen to be $11.9 \mathrm{keV}$ and the focus size was set to $1(\mathrm{~h}) \times 0.04(\mathrm{v}) \mathrm{mm}^{2}$. Therefore, we followed the surface evolution by GISAXS with the 2D detector (XPAD3 Hybrid Pixel Detector, pixel size $130 \mu \mathrm{m} \times 130 \mu \mathrm{m})$ [24] and detected GIXRPD and XRR with the point detector (Model Cyberstar, Echirolles cedex, France) (see Fig. 2). Therefore, the measuring routine was to start the deposition and to follow the structural evolution with GISAXS. In turn, GIXRPD and XRR were performed after the deposition and after the annealing, respectively. For the latter, see Fig. 5. For more details on the data handling and analysis, see "Results and discussion" section.

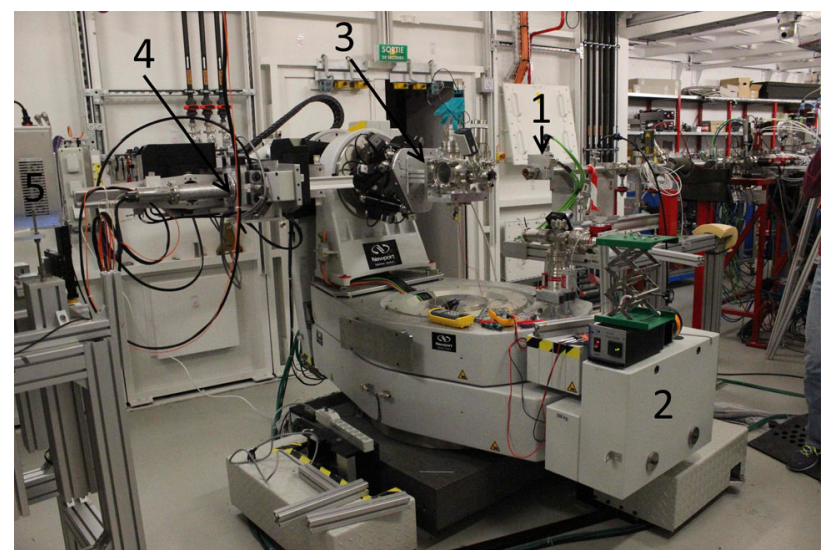

Figure 2 The sputtering chamber installed at the surface and interface X-ray beamline SIXS at SOLEIL. The photograph shows: (1) X-ray flight tube, (2) high-resolution diffractometer, (3) sputtering unit, (4) point detector and (5) 2D detector.

\section{GISAXS}

For this experiment, the sample-to-detector distance (SDD) was $2.4 \mathrm{~m}$ and the incidence angle was $0.4^{\circ}$. To still perform the GIXRPD and XRR measurements, we could not install a flight tube in front of the GISAXS detector. Due to the weak refraction index of $\mathrm{BaTiO}_{3}$ and the high background noise from the Kapton ${ }^{\circledR}$ windows of the chamber, and the air scattering, we used an exposure time for the patterns of $10 \mathrm{~s}$. Due to the long exposure time, we reduced the sputtering power at the target to slow down the deposition process. For all, that the experiment yielded to a series of 2D GISAXS pattern of the thin film formation. Exemplarily, Fig. 3 depicts a GISAXS pattern after $300 \mathrm{~s}$ of deposition at $400{ }^{\circ} \mathrm{C}$ with the scattering peaks of an early thin film formation. Also marked in the figure are the primary beam position, the Yoneda wings in the level of the Yoneda peak [25], the reflected beam and the beam stop. As it can

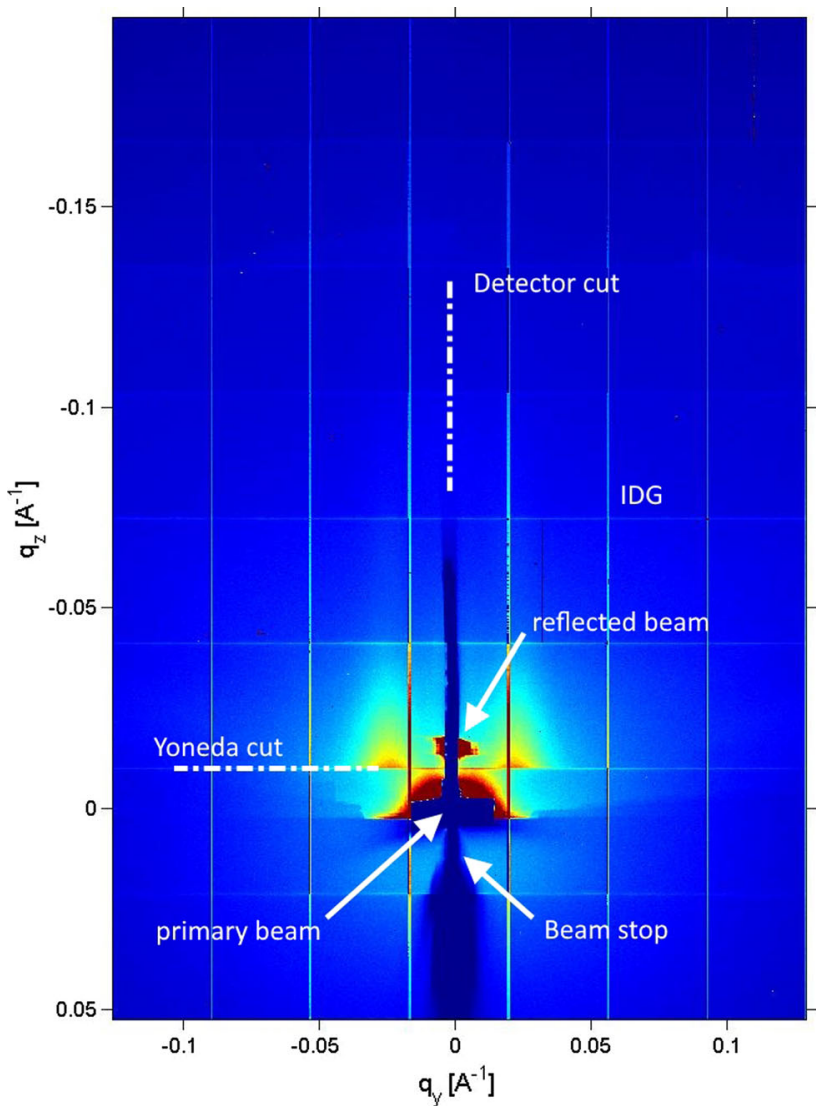

Figure 3 Exemplary two-dimensional GISAXS false color plot of $\mathrm{BaTiO}_{3}$ after $300 \mathrm{~s}$ of deposition at $400{ }^{\circ} \mathrm{C}$. Denoted are the beam stop, the out of plain cuts (Yoneda cut and detector cut) and the inter-modular detector gaps (IDG). 
be seen, we were using one beam stop for both: the direct and reflected beam. The recording of the data started five patterns before opening the shutter. These five pictures were used to determine the background for the data analysis. Figure 4 shows the background-subtracted data of Fig. 3 (left) and the temporal evolution of the Yoneda peaks (upper right) and four exemplary fits of the Yoneda peaks at 100, 300,400 and $600 \mathrm{~s}$.

\section{GIXRPD}

The GIXRPD measurement at the beamline SIXS was performed with the point detector. For that, we also used the on-the-fly method, performing with $4^{\circ} / \mathrm{s}$. The corresponding incident angle was $0.4^{\circ}$. Figure 5 shows a GIXRPD plot of the film from Fig. 6c after the annealing of the thin film to $700{ }^{\circ} \mathrm{C}$ for $10 \mathrm{~min}$, which leads to the crystallization of $\mathrm{BaTiO}_{3}$ identifiable by the structure peaks, which are marked in the figure.

\section{$X R R$}

Subsequent to deposition, XRR dataset was recorded on the as-deposited thin film. This was done using the point detector installed at the detector arm of the diffractometer. With the fast absorber system [26] of the SIXS beamline, the XRR measurement could be done on the fly in a time of $30 \mathrm{~s}$ for $3^{\circ}$. Depending on the performed experiment in terms of deposition temperature and a subsequent annealing, XRR measurements were carried out before and after the annealing. Figure 6 shows a thin film deposited on a Si substrate at a temperature of $100{ }^{\circ} \mathrm{C}$ and annealed for 10 minute to a temperature of $700{ }^{\circ} \mathrm{C}$ to induce crystallization. The data were fitted using the Parratt algorithm [27]. The corresponding layer model to the fits is shown in Fig. 6b, c. All figures and results in this subsection belong to the same thin film. Using the $2 \mathrm{D}$ detector and the point detector with the onthe-fly measuring mode is a great option to investigate the growth of thin films in situ which can only be optimized by using two 2D detectors to perform GISAXS and GIXRPD simultaneously.

\section{Measuring with two 2D detectors}

For the measurements at P08, the chamber was installed at the six-circle diffractometer. This

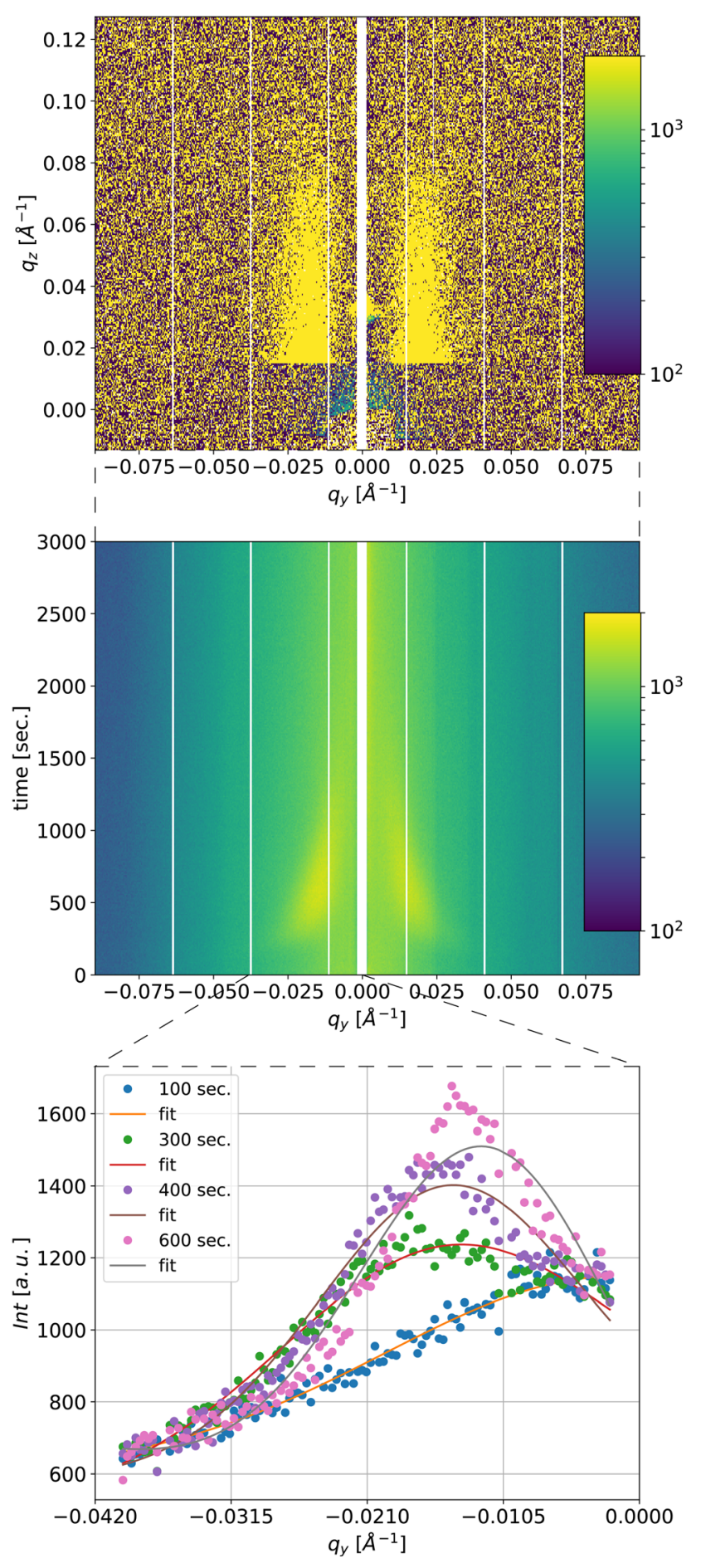

Figure 4 Background-free GISAXS signal after $300 \mathrm{~s}$ of deposition at $400{ }^{\circ} \mathrm{C}$ (top) and temporal intensity evolution of horizontal cuts at the Yoneda peak (middle) and of the pseudoVoigt fits of the Yoneda cuts (bottom). The data points displaying the background-subtracted data and the lines the corresponding pseudo-Voigt fit. 


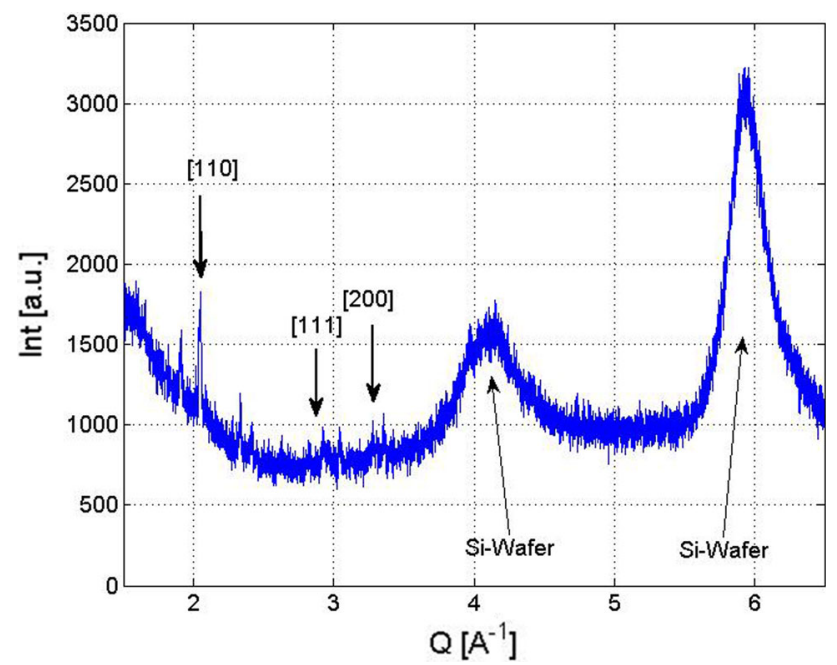

Figure 5 GIXRPD data taken with the point detector at the surface interface X-ray scattering beamline SIXS at SOLEIL. Shown is the region from 1.7 to $6.3 \AA^{-1}$, and marked are the polycrystalline powder diffraction peaks from $\mathrm{BaTiO}_{3}$ and the broad peaks from Si wafer structure [38].

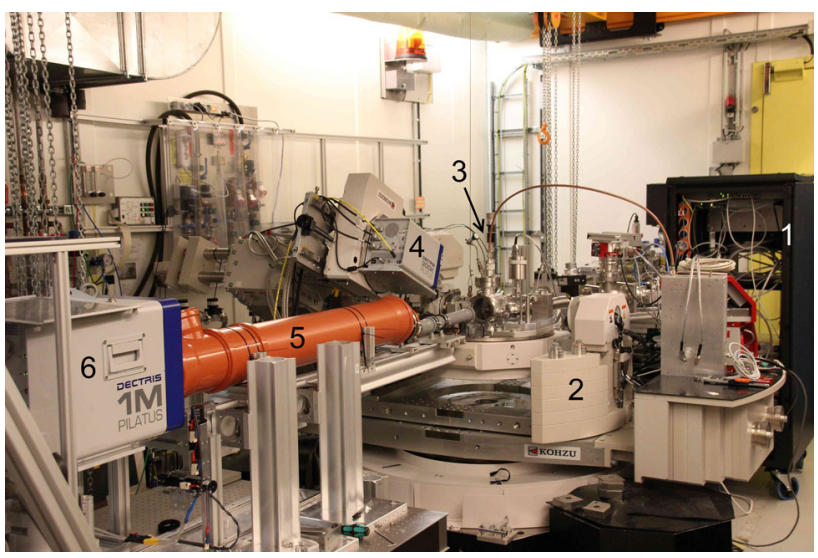

Figure 7 Experimental setup at the surface diffraction beamline P08 at PETRA III at DESY, Hamburg. Shown are the electronic rack (1), the high-resolution diffractometer (2), the deposition unit (3), the 2D GIXRPD detector (4), the temporary installed He-filled flight tube (5) and the 2D GISAXS detector. The angles of both detectors were fixed during the measurement, and both detectors were running simultaneously.

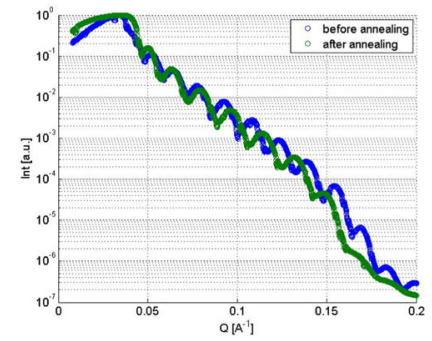

(a) XRR before and after anealing.

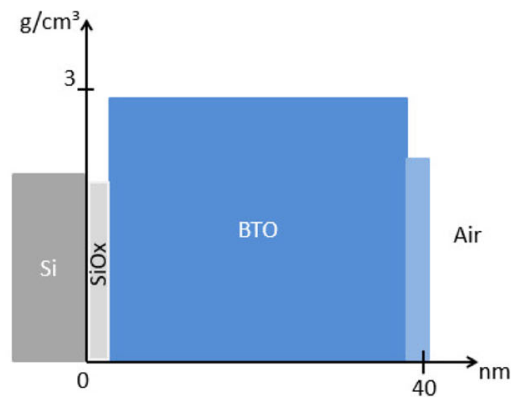

(b) Density and layer sequence model before anealing.

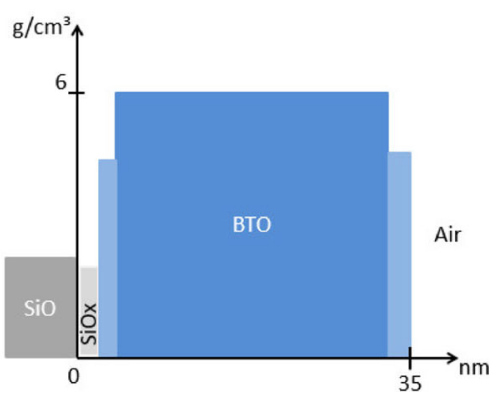

(c) Density and layer sequence model after anealing.

Figure 6 XRR measurements SIXS and density profiles. a Shows two XRR measurements, before and after the annealing to $700{ }^{\circ} \mathrm{C}$ for 10 min. $\mathbf{b}$ Shows the corresponding density profile for the amorphous $\mathrm{BaTiO}_{3}$ thin film. $\mathbf{c}$ Shows the density profile after the annealing..

diffractometer is specially designed to accommodate the small beam height of $1 \mathrm{~m}$ and is of extreme high precision with $2 \times 10^{-15}$ resolution of the main axes and less than $15 \mu \mathrm{m}$ sphere of confusion (see Fig. 7) [23]. The focal size was $0.5(\mathrm{~h}) \times 0.4(\mathrm{v}) \mathrm{mm}^{2}$. We have used for the GISAXS during the deposition and the XRR after the deposition a single-photon counting pixel detector with $981 \times 1043$ pixels of $172 \mu \mathrm{m}^{2}$ each (Model Pilatus 1M, Dectris Baden, Switzerland). The detector was installed on a xyz-translation stage. This stage was used to move the detector during the XRR measurement to cover the inter-modular detector gaps of the detector. A second single-photon counting pixel detector with $487 \times 619$ pixel of $172 \mu \mathrm{m}^{2}$ each (Model Pilatus 300k, Dectris, Baden,
Switzerland) was mounted on the detector arm of the diffractometer. With this second 2D detector, we were following the evolution by GIXRPD simultaneously to the GISAXS measurement. The offset of the GIXRPD detector allowed the installation of a flight tube filled with $\mathrm{He}$ gas to minimize air scattering. With this installation of the two detectors, we could follow the evolution of the growing thin film over a large Q-space range. The X-ray energy was $11 \mathrm{keV}$, and the exposure time was $2 \mathrm{~s}$ for both detectors, including all the information given by GISAXS and GIXRPD as mentioned in "Experimental techniques" section. A brief discussion about the information given by these measurements is given in "Results and discussion" section. 
Figure 8 Exemplary region of the GISAXS detector of the twodimensional GISAXS pattern taken at the surface diffraction beamline P08 at PETRA III (top). Denoted are the beam stop, the Yoneda level, the inter-modular detector gaps (IDG), the direct beam and the outer edge of the experiment horizon limited by the flight tube. The intensity evolution of the horizontal cuts at the level of the Yoneda peak (middle). And the pseudo-Voigt fits of the Yoneda cuts (bottom). The date points displaying the background-subtracted data and the lines the corresponding fit.

\section{GISAXS}

The GISAXS patterns were taken with a time resolution of $2 \mathrm{~s}$ without any movement of the detector and a beam stop fix installed in front of the detector to cover the primary and the reflected beam (see Fig. 8). The detector was installed with a sample-todetector distance of $2.09 \mathrm{~m}$, and the incident angle was $0.4^{\circ}$. The flight tube was filled with He gas which has the advantage of minimizing the air scattering and reducing the absorption, but nevertheless, the Kapton foil at both ends of the flight tube itself increases the background due to scattering. But this, in turn, has a lower effect than pure air scattering over the whole distance from the chamber to the detector. Furthermore, the position and size of the beam stop are crucial for the data quality: It should be as close to the sample as possible to catch the air scattering from the primary beam and at the same time small enough to not cover the small-angle scattering signal. The flight tube was a temporary installation. Therefore, for practical reasons, the beam stop was installed at the end of the flight tube close to the exit window. As an example, Fig. 8 shows a region of interest of the GISAXS pattern after $10 \mathrm{~s}$ of deposition on a substrate at $500{ }^{\circ} \mathrm{C}$ and also the intensity evolution of the Yoneda cuts and a series of selected fits for the early stage of deposition.

\section{GIXRPD}

The second detector was used for GIXRPD and was installed under a fixed two-theta angle of $22^{\circ}$ with a SDD of $672 \mathrm{~mm}$. Both detectors were triggered simultaneously. Thus, we were able to follow the formation and growth of the thin film in the range from 1.9 to $2.8 \AA^{-1}$ simultaneously to the small-angle range. When depositing at temperatures above $500{ }^{\circ} \mathrm{C}$, the crystallization occurred during the

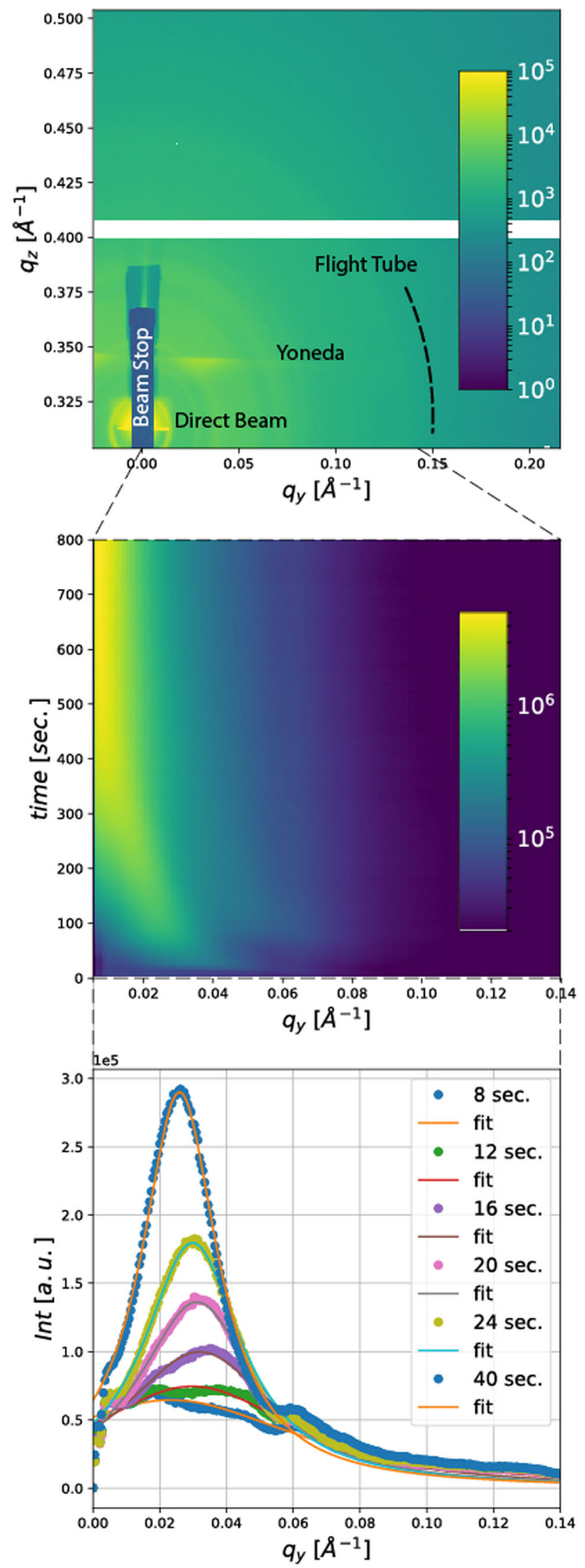


deposition and did not have to be induced by annealing the sample after deposition. The crystallization is indicated by the occurrence of powder diffraction rings on the left-hand side of Fig. 9. The right-hand side of Fig. 9 shows the corresponding azimuthally integrated GIXRPD pattern.

\section{$X R R$}

These results can be complemented with the information from XRR measurements. In case of layer-bylayer growth with correlated roughness, as it is the case in Fig. 12a, one can extract the equidistant intensity modulations from the GISAXS patterns to get information about the film thickness during the whole thin film evolution. Otherwise, the XRR measurements have to be done after the deposition. The XRR measurement also can be done before and after annealing a thin film. Figure 10 shows the reflectivity measurements after the deposition of a $\mathrm{BaTiO}_{3}$ thin film.

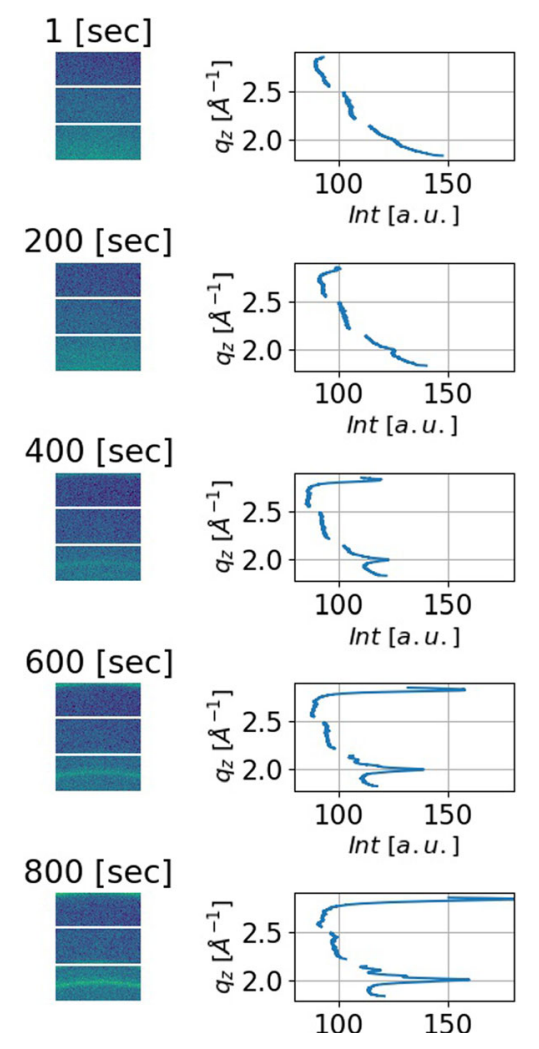

Figure 9 Exemplary two-dimensional GISAXS pattern during the deposition at $500{ }^{\circ} \mathrm{C}$ on the left-hand side and the corresponding azimuthally integrated GIXRPD pattern on the right-hand side.
To measure the reflectivity after the deposition, the GISAXS detector stage was moved along the $q_{y}$ direction, because the beam stop was also attached to this stage. Consequently, the $X$-rays were hitting the detector in a different spot. For the first step, the Xray beam was attenuated due to the high intensities in the critical angle regime. Additionally, during the XRR measurements, the detector was moved in $q_{z^{-}}$ direction three times to cover the inter-modular detector gaps. During the XRR measurements, the detector was moved in height three times. The different absorption levels were defined prior to the measuring and were fixed during the three measurements. While the detector was at a fixed position, we had to rotate the sample for the reflectivity measurements. The data were merged and analyzed using the Parratt formalism (see results in Fig. 10).

\section{Results and discussion}

With the experimental setup and the methods described above, we were able to follow the influence of the different preparation parameters by measuring at different substrate temperatures and different substrate materials. To demonstrate the capabilities of combined measurements, we present selected results. The systematic analysis of the substrate material and substrate temperature is not in the scope of this paper and will thus be published elsewhere.

The thin film formation is strongly energy dependent $[5,6]$. The early nucleation is a product of three terms $N=N^{*} \cdot A^{*} \cdot \omega$, with $N^{*}$ the equilibrium concentration of the stable nuclei and $\omega^{*}$ the rate at which atoms impinge on the nuclei of critical area $A^{*}$ [28]. With the thermodynamic criterion for the growth mode developed by $\mathrm{E}$. Bauer, the equilibrium condition is given by $\Delta \sigma=\sigma_{\mathrm{f}} \cdot \sigma_{\mathrm{i}} \cdot \sigma_{\mathrm{s}}$, where $\sigma_{\mathrm{f}}$ is the free energy of the film, $\sigma_{\mathrm{i}}$ is the free energy of the interface, and $\sigma_{\mathrm{s}}$ is the free energy of the surface $[28,29]$. The free energy can hence be exploited toward the three known growth models, i.e., layerby-layer, island and island plus layer growth [30, 31]. However, in general it can be stated that higher substrate temperatures favor fewer but larger nuclei, whereas higher deposition rates favor more and smaller nuclei. Thus, if one uses high temperatures and also low deposition rates, epitaxial growth is facilitated [30-32].

\section{Springer}




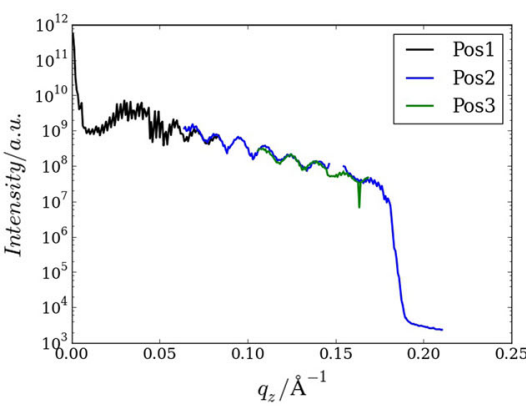

(a) Original data of the three merged position of XRR measurement.

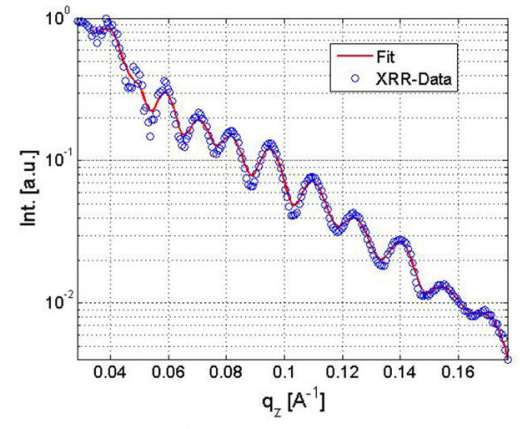

(b) XRR data and fit.

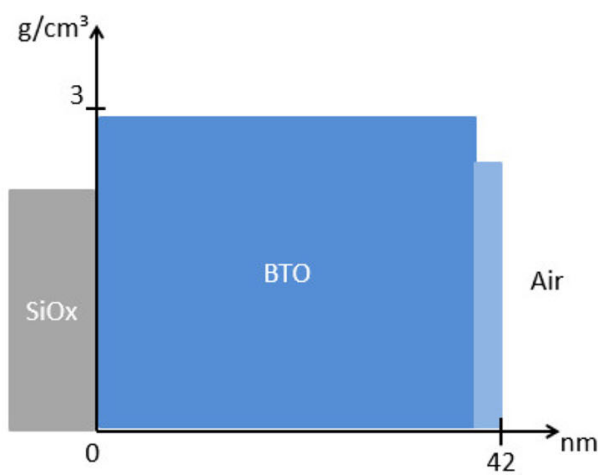

(c) Density and layer sequence model.
Figure $10 \mathrm{XRR}$ data, data fit and density profile after the deposition of $\mathrm{BaTiO}_{3}$ at $100{ }^{\circ} \mathrm{C}$. a Shows the data according to the three different detector positions. $\mathbf{b}$ Shows the data and the result of the Parratt formalism fit. c Shows the corresponding density and layer sequence model of the fit.
Figure 11 Horizontal line cuts versus deposition time and results of data fits. The upper row on the left shows a 2D map showing the temporal intensity evolution of the Yoneda cuts versus deposition time for the first $100 \mathrm{~s}$ of deposition at $500{ }^{\circ} \mathrm{C}$. The upper row on the right shows the results of the pseudo-Voigt data fits regarding $10 \mathrm{a}$. Shown is the evolution of the position and $\sigma$. The lower row on the left shows a 2D map showing the temporal intensity evolution of the Yoneda cut versus deposition time for the first $100 \mathrm{~s}$ of deposition at $600{ }^{\circ} \mathrm{C}$ and on the right side the results of the pseudo-Voigt data fits.
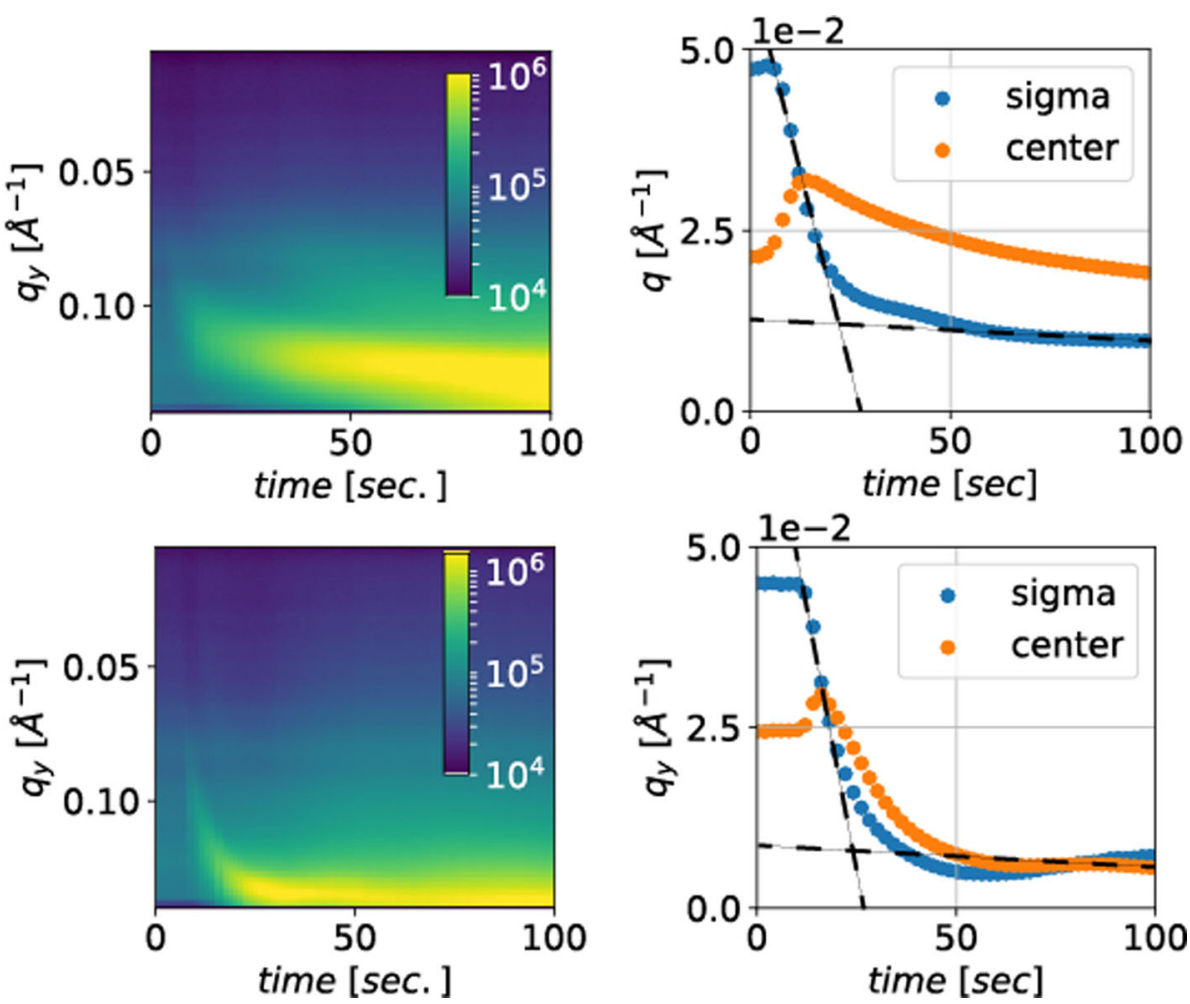

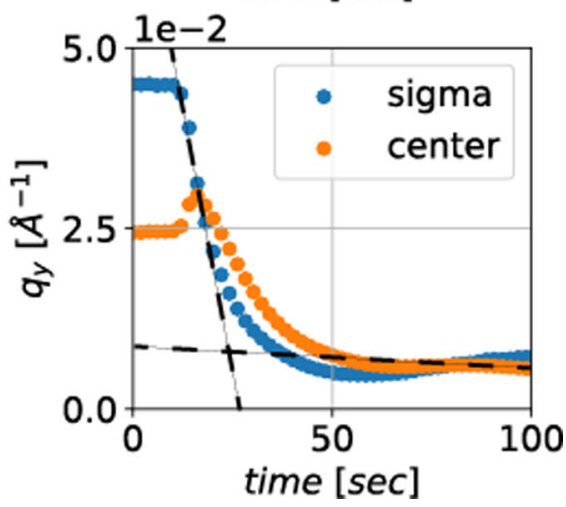

With the 2D GISAXS patterns collected during the experiments, we were able to follow the evolution of the thin film from the first nucleation. This is visualized in Fig. 11, which shows contour plots of the out-of-plane cuts (Yoneda cuts) of the early formation of $\mathrm{BaTiO}_{3}$ on a $\mathrm{SiO}_{2}$ wafer at $500{ }^{\circ} \mathrm{C}$ and at $600{ }^{\circ} \mathrm{C}$ versus the first $100 \mathrm{~s}$ of deposition. Within this work, we show the influence of the free surface energy by varying the deposition temperature.
The evolution is depicted in the shift of the peak position, the decrease in its position, FWHM and the amplitude. This information was extracted from pseudo-Voigt fits (see Fig. 8). The shift to lower $q_{y}$ values over time is related to an increase to the center-to-center distance $\mathrm{D}$ between $\mathrm{BaTiO}_{3}$ clusters. The relation $D \approx 2 \pi / q$ enables us to track the mean cluster distance during the growth as a quantitative parameter. A transition to an adsorption-driven cluster 
growth regime from a diffusion-mediated coalescence regime can be observed from the evolution of the FWHM (see Fig. 11). Since there was no change in the sputtering source parameters, the amount of arriving particles can be considered as constant for both temperatures. Hence, the transition from fast increasing ordering to a slower growth of a two-dimensional cluster growth, indicated by the change in the slope at $45 \mathrm{~s}$ of deposition at $500{ }^{\circ} \mathrm{C}$ and $40 \mathrm{~s}$ for $600{ }^{\circ} \mathrm{C}$, respectively, is equal. The evolution of the out-of-plane cuts of the thin films shows a temperature-dependent difference in terms of position and amplitude. This means with higher temperatures, larger clusters are achieved in shorter time ranges, which correspond to our description above.

The evolution of the vertical scattering features is depicted in Fig. 12a, b. It shows the off-detector line cuts versus the deposition time at $100{ }^{\circ} \mathrm{C}$ and $500{ }^{\circ} \mathrm{C}$. In Fig. 12a, the appearance of equidistant intensity modulations relates to the growing average film thickness along the detector axis $q_{z}$ and indicates amorphous layer growth during the deposition at $100{ }^{\circ} \mathrm{C}$. Missing polycrystalline rings in the simultaneous running GIXRPD detector also indicate an amorphous state of the thin film. A layer-by-layer growth for $\mathrm{BaTiO}_{3}$ is well known in the low deposition temperature region $[7,13]$. In contrast, the off-detector cuts in Fig. 12b during the deposition at $500{ }^{\circ} \mathrm{C}$, indicate no equidistant layer-by-layer growth which correspond to the appearance of growing clusters as suggested from the Yoneda cuts at high temperatures (see Fig. 11a). This result is proven by the appearance of polycrystalline rings in the GIXRPD detector (see Fig. 16).

After the deposition of the thin films, atomic force microscopy (AFM) measurements were taken. Exemplary data are shown in Fig. 12c, d. The results show a rather smooth surface with a rms roughness of $(2.5 \pm 0.2) \mathrm{nm}$ for the deposition at $100{ }^{\circ} \mathrm{C}$ and a rough surface of $(19.4 \pm 1.9) \mathrm{nm} \mathrm{rms}$ for the deposition at $500{ }^{\circ} \mathrm{C}$. The smooth surface measured with the AFM translates to the described thin film formation of layer-by-layer growth through the whole film evolution. The AFM measurement of the high temperature deposition shows a surface of hemispherical (dome shape) thin film formation.

As described above, XRR measurements were taken after the deposition. Due to the high surface roughness at $500{ }^{\circ} \mathrm{C}$, the XRR measurement was not possible [27]. Table 1 shows the results for depositions below the crystallization energy. And Table 2 shows the roughness determined with an AFM. In
Figure 12 Detector line cuts (along $q_{z}$ ) versus deposition time for the deposition temperature of $100{ }^{\circ} \mathrm{C}$ (a) and $500{ }^{\circ} \mathrm{C}(\mathbf{b})$. Equidistant modulations in the $q_{z}$ direction occur during the deposition at low surface energy (substrate temperature of $100{ }^{\circ} \mathrm{C}$ ) indicating contentious amorphous layer-by-layer growth with correlated roughnesses but not at the deposition temperature of $500{ }^{\circ} \mathrm{C}$. Also shown are AFM measurements after $100{ }^{\circ} \mathrm{C}$ (c) and $500{ }^{\circ} \mathrm{C}$ (d).

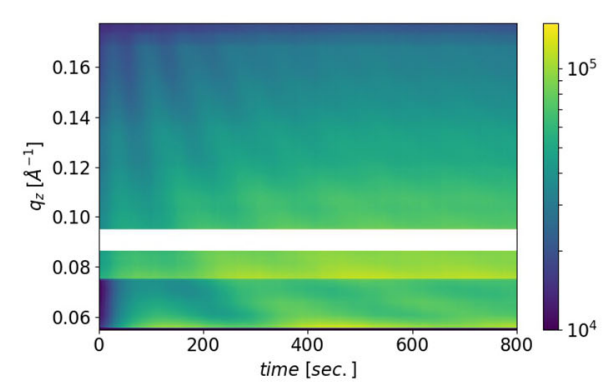

(a) Detector cut during $100^{\circ} \mathrm{C}$ deposition temperature

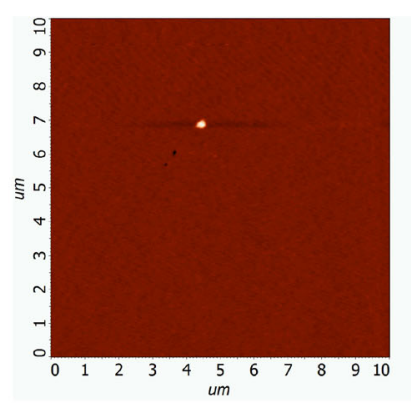

(c) AFM measurement taken after the deposition at $100^{\circ} \mathrm{C}$

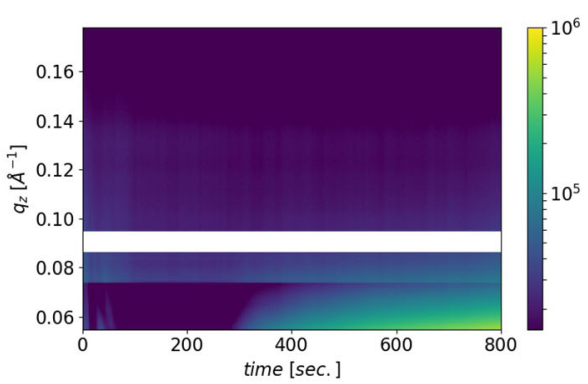

(b) Detector cut during $500^{\circ} \mathrm{C}$ deposition temperature

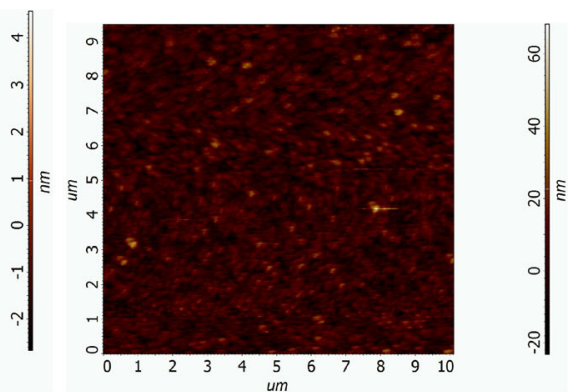

(d)AFM measurement taken after the deposition at $500^{\circ} \mathrm{C}$ 
Table 1 Results of the XRR measurements after the deposition with different temperatures

\begin{tabular}{llll}
\hline Temp. $\left({ }^{\circ} \mathrm{C}\right)$ & Thickness $(\mathrm{nm})$ & Density $\left(\mathrm{g} \mathrm{cm}^{-3}\right)$ & Roughness $(\mathrm{nm})$ \\
\hline 100 & $41.8 \pm 0.2$ & $3.0 \pm 0.2$ & $2.1 \pm 0.3$ \\
300 & $41.5 \pm 0.2$ & $3.2 \pm 0.3$ & $2.5 \pm 0.4$ \\
400 & $37.1 \pm 0.4$ & $4.7 \pm 0.4$ & $8.1 \pm 0.4$ \\
\hline
\end{tabular}

terms of roughness, the results of the XRR and AFM measurements are in good agreement. The surface roughness ascertained from the AFM measurement for the temperatures at $500{ }^{\circ} \mathrm{C}$ and $600{ }^{\circ} \mathrm{C}$ explains why the XRR measurements were not possible. Also, the findings from the ARM and XRR measurement are in good conclusion with the film evolution described above.

To further emphasize the quantitative results of our data, we fit the 2D GISAXS pattern taken during the thin film evolution. To simulate and fit the data, we used the software BornAgain (BA) [33]. BornAgain is a software package to simulate and fit smallangle scattering at grazing incidence. The greatest advantage of BornAgain compared to other software, which is also used to analyze GISAXS data, is the ability to fit data and not only to simulate it. At first, we fit the pattern taken after $200 \mathrm{~s}$ of deposition at $100{ }^{\circ} \mathrm{C}$ on $\mathrm{SiO}_{2}$. The model that fits the best is the formation of two layers of amorphous and randomly distributed small $\mathrm{BaTiO}_{3}$ cylinders with a height of $5 \mathrm{~nm}$ and a diameter of $3 \mathrm{~nm}$ and a particle density of

Table 2 Results of the AFM measurements after the deposition with different temperatures

\begin{tabular}{lc}
\hline Temp. $\left({ }^{\circ} \mathrm{C}\right)$ & Roughness $(\mathrm{nm})$ \\
\hline 100 & $2.5 \pm 0.2$ \\
300 & $5.9 \pm 0.9$ \\
400 & $11.4 \pm 4.5$ \\
500 & $19.3 \pm 1.9$ \\
600 & $22.5 \pm 3.1$ \\
\hline
\end{tabular}

70\%. The difference between the two layers is the particle density. This fit result matches the information obtained of the out-of-plane cuts. Figure 13 shows simulations of the thin film evolution with correlated roughness as described above and the corresponding fit. As second fitting result, we like to show the fitting of the early formation during the deposition at $600{ }^{\circ} \mathrm{C}$. These results are shown in Fig. 14. It depicts a ROI of the 2D pattern on the left of the beam stop after 2, 6 and $12 \mathrm{~s}$ and the simulated data for the data fit. The best fitting model is a hemiellipsoid cluster on a hexagonal lattice, with good agreements of the cluster size to the calculated size from the geometrical pseudo-Voigt assumptions $(4 \mathrm{~nm}$ for $2 \mathrm{~s}$ and $10 \mathrm{~nm}$ for $10 \mathrm{~s} \pm 1 \mathrm{~nm}$ ). This shows the basic qualitative and quantitative information one can gain out of the GISAXS data.

These exemplary GISAXS analyses become even more powerful when they are combined with the GIXRPD data (see Fig. 16). It shows the azimuthal integrated intensity of the GIXRPD detector versus time (Fig. 16a) plus the width (Fig. 16b) and peak intensity (Fig. 16c) behavior from $\mathrm{BaTiO}_{3}$ during the deposition at $500{ }^{\circ} \mathrm{C}$. We have shown a adsorptiondriven cluster growth during the deposition at this temperature. After $220 \mathrm{~s}$ of deposition and cluster growth, the crystallization occurs as it can be seen in Fig. 16b, c, and highlighted are the nonlinear least squares fits. The constant width indicates a homogeneous average polycrystallization size, and the increasing amplitude corresponds to the quantity of diffraction sources, i.e., crystallites [34]. Figure 15
Figure 13 Exemplary GISAXS pattern and fit of $\mathrm{BaTiO}_{3}$ after 200 of deposition at $100{ }^{\circ} \mathrm{C}$. Shown is a model layer-by-layer growth with 2 layers of correlated roughens built from cylinders with a height of $5 \mathrm{~nm}$ and a diameter of $3 \mathrm{~nm}$
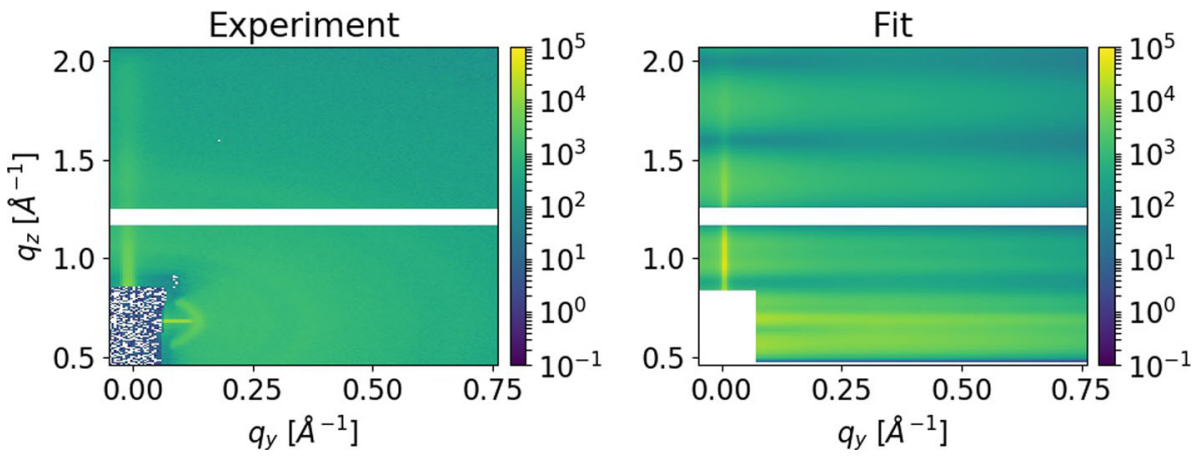
Figure 14 Exemplary GISAXS pattern and fit of $\mathrm{BaTiO}_{3}$ after 2, 6 and $12 \mathrm{~s}$ of deposition at $600{ }^{\circ} \mathrm{C}$. Shown is a model of hemi-ellipsoids clusters on a hexagonal lattice with a size of $3 \pm 1 \mathrm{~nm}$ after $2 \mathrm{~s}, 4 \pm 1 \mathrm{~nm}$ after $6 \mathrm{~s}$ and $5 \pm 1 \mathrm{~nm}$ after $12 \mathrm{~s}$, respectively.
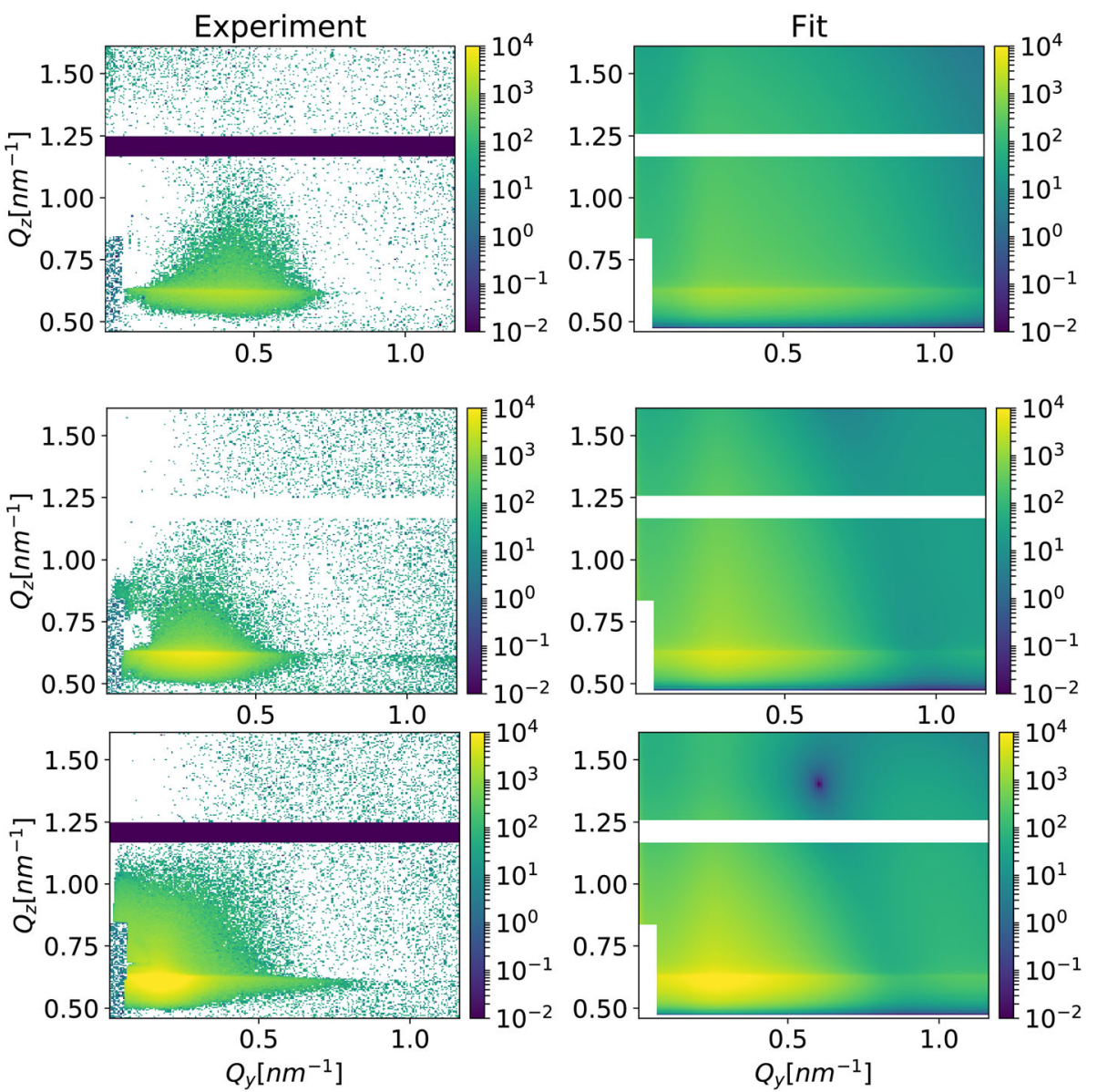

shows the comparison of the cluster size taken from the pseudo-Voigt fit and the simulations. The large error bars are the result of the signal-to-noise ratio in the early stage of formation. In this phase of deposition, the bigger part of detected scattering are from the Kapton windows of the flight tube (see Fig. 8). This also shows the amount of information that is in the $2 \mathrm{D}$ pattern compared to a small $\mathrm{ROI}$ in the plane of the Yoneda wings. Measurements at $500{ }^{\circ} \mathrm{C}$ and $600{ }^{\circ} \mathrm{C}$ have shown that the crystallization behavior is different in time and crystallization speed of the entire material. We were able to follow the crystallization of an oxide thin film with GISAXS and GIXRPD, to our best knowledge, for the first time in situ during the deposition. The detailed results to this will be presented in a different publication.

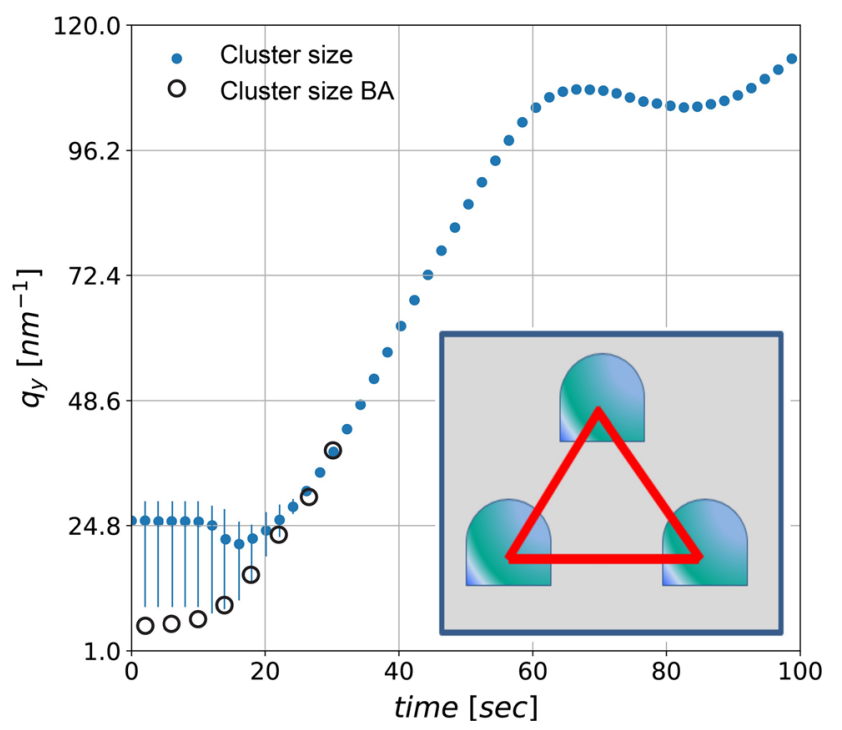

Figure 15 Calculated cluster size from the pseudo-Voigt fits of the Yoneda cut data and BornAgain [BA] fits during the deposition at $600{ }^{\circ} \mathrm{C}$. Shown is a model of hemi-ellipsoids clusters on a hexagonal lattice with a size of $3 \pm 1 \mathrm{~nm}$ after $2 \mathrm{~s}$, $4 \pm 1 \mathrm{~nm}$ after $6 \mathrm{~s}$ and $5 \pm 1 \mathrm{~nm}$ after $12 \mathrm{~s}$, respectively. 


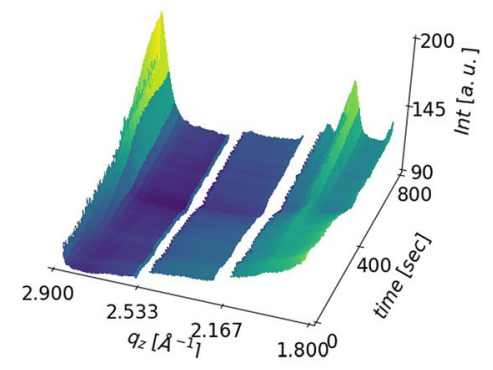

(a) Azimuthally integrated GIXRPD pattern versus time.
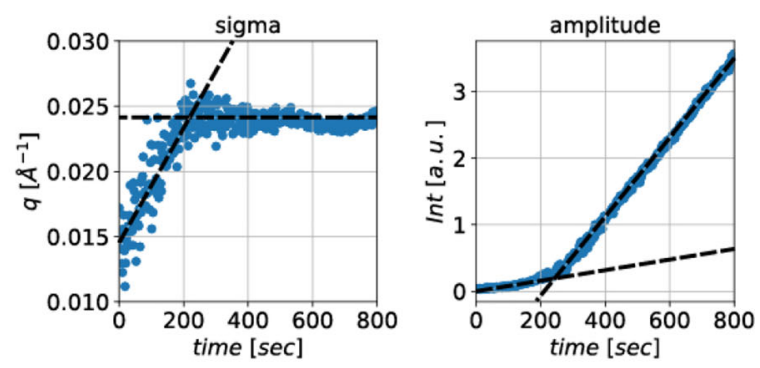

(b) Evolution of the $2 \AA$ peak width and amplitude versus deposition time.
Figure 16 Evolution of the $\mathrm{BaTiO}_{3}$ peaks. a Shows the azimuthally integrated patterns versus deposition time. $\mathbf{b}$ Shows the evolution of the peak width and amplitude of the peaks during the deposition at $500{ }^{\circ} \mathrm{C}$ and indicates a peak growth due to crystallization after $220 \mathrm{~s}$ of deposition.
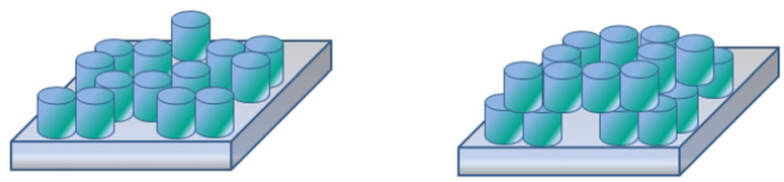

(a) Thin film evolution $\leq 400^{\circ} \mathrm{C}$.
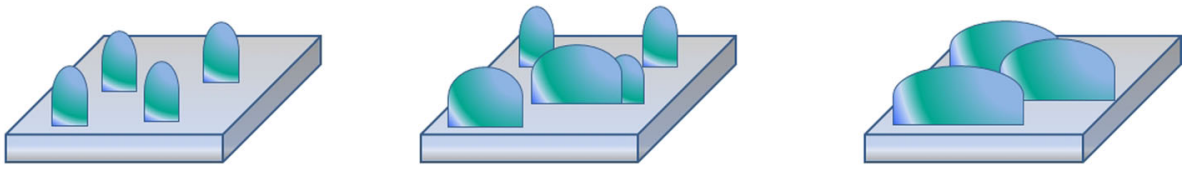

(b) Thin film evolution $\geq 500^{\circ} \mathrm{C}$.

\section{Summary and outlook}

There is a lot of literature that describes the thin film formation in theory and experiment, where most of it is based on ex situ investigations [35-37]. In this work, we demonstrated an in situ investigation of the entire thin film evolution in real time and ways of quantitative and qualitative analysis of the data. We proved that this is a powerful technique to investigate the dynamics of the crystallization to gain a real advantage of tailoring application optimized thin films. It has been observed that the temperature has a clear influence on the film structure and morphology during all stages of deposition. This correlation is discussed in the context of an established scientific model. In contrast to the temperature, the choice of substrate material decreasingly affects the film properties with increasing layer thickness. Finally, the crystallization of the films was shown throughout the thickness of the deposited layer and to be largely temperature dependent. Figure 17 displays the thin film evolution at temperatures of $400{ }^{\circ} \mathrm{C}$ and less as well as above $500{ }^{\circ} \mathrm{C}$. The shown experimental setup can be further improved with the use of two beam stops: one for the direct beam and one for the specular beam to get all of the information coming from the Yoneda peak. And for the crystallization of thin films, one can gain more information by placing the GIXRPD detector in the plain direction of the substrate.

\section{Acknowledgements}

The authors gratefully acknowledge K. Pflaum, J. Blume, L. Wilke, M. Fleck and H. Zink and the FS-EC group. Because of their work and efforts, the sputtering unit is operational. We further thank F. Bertram, R. Doehrmann, K. Schlage and U. Ruett from the FS-PE group for fruitful discussions and help 
during the different beam times. For help in creating the graphic Fig. 1., we are indebted to J. Frerichs.

\section{References}

[1] Franz G (2009) Low pressure plasmas and microstructuring technology. Springer, Berlin

[2] Ohring M (1991) Materials science of thin films. Wiley, New York

[3] Thornton JA (1974) Influence of apparatus geometry and deposition conditions on the structure and topography of thick sputtered coatings. J Vacuum Sci Technol 11:666

[4] Thornton JA (1977) High rate thick film growth. Annu Rev Mater Sci 7:239-260

[5] Thornton JA (1986) The microstructure of sputter-deposited coatings. J Vacuum Sci Technol A Vacuum Surf Films 4:3059

[6] Anders A (2010) A structure zone diagram including plasma-based deposition and ion etching. Thin Solid Films 518:4087-4090

[7] Walter P, Dippel A-C, Pflaum K, Wernecke J, van den Hurk J, Blume J, Klemradt U (2015) A compact and low-weight sputtering unit for in situ investigations of thin film growth at synchrotron radiation beamlines. Rev Sci Instr 86:053906

[8] Tynell T, Karppinen M (2015) Inorganic-organic superlattice thin films by atomic/molecular layer deposition. In: Mele P, Endo T, Arisawa S, Li C, Tsuchiya T (eds) Oxide thin films, multilayers, and nanocomposites. Springer, Cham. https://d oi.org/10.1007/978-3-319-14478-8_9

[9] Wainer E, Solomon AN (1942) The structure of ferroelectric sodium niobate at room temperature. Titanium Alloy Manufacturing Co. Report No. 8, 3

[10] Wul BM, Goldman IM (1945) Dielectric constant of barium titanate as a function of strength of an alternating field. Compt Rend Acad Sci URSS 46:154-57

[11] Ogawa T (1947) On barium titanate ceramics. Busseiron Kenkyo (in Japanese) 6:1-27

[12] Gonzalo JA, Jimenez B (2005) Ferroelectricity. Wiley, VCH Verlag Weinheim

[13] Lines ME, Glass AM (2001) Principles and application of ferroelectrics and related materials. Oxford University Press Inc, New York

[14] d Araujo CP, Scott JF, Taylor GW (1996) Ferroelectric thin films: synthesis and basic properties. Gordon and Breach Publishers, Amsterdam

[15] Rödel J, Jo W, Seifert KTP, Anton EM, Granzow T, Damjanovic D (2009) Perspective on the development of leadfree piezoceramics. J Am Ceram Soc 92:1153-1177
[16] Valencia S, Crassous A, Bocher L, Garcia V, Moya X, Cherifi RO, Deranlot C, Bouzehouane K, Fusil S, Zobelli A, Gloter a, Mathur ND, Gaupp A, Abrudan R, Radu F, Barthélémy A, Bibes M (2011) Interface-induced room-temperature multiferroicity in batio3. Nat Mater 10:753-8

[17] Tenne DA, Bruchhausen A, Lanzillotti-Kimura ND, Fainstein A, Katiyar RS, Cantarero A, Soukiassian A, Vaithyanathan V, Haeni JH, Tian W, Schlom DG, Choi KJ, Kim DM, Eom CB, Sun HP, Pan XQ, Li YL, Chen LQ, Jia QX, Nakhmanson SM, Rabe KM, Xi XX (2006) Probing nanoscale ferroelectricity by ultraviolet Raman spectroscopy. Science 313:1614-6

[18] Depla D, Mahieu S (2008) Reactive sputter deposition. Springer, Berlin

[19] Schwartzkopf M, Buffet A, Körstgens V (2013) From atoms to layers: in situ gold cluster growth kinetics during sputter deposition. Nanoscale 5:5053-5062

[20] Bommel S, Kleppmann N, Weber C, Spranger H, Schäfer P, Novak J, Roth S, Schreiber F, Klapp S, Kowarik S (2014) Unravelling the multilayer growth of the fullerene c60 in real time. Nat Commun 5:5388

[21] Liu T, Hou J, Wang B, Bai F, Chen H, Gao L, Cao Y, He H, Wang J, Wang N, Cao G, Guo Z (2016) Correlation between the in-plain substrate strain and electrocatalytic activity of strontium ruthenate thin films in dye-sensitized solar cells. J Mater Chem A 00:1-7

[22] Baudelet F, Belkhou R, Briois V, Al E (2005) SOLEIL a new powerful tool for materials science. Oil Gas Sci 60:849-874

[23] Seeck O, Deiter C, Pflaum K, Bertam F, Beerlink A, Franz H, Horbach J, Schulte-Schrepping H, Murphy BM, Greve M, Magnussen O (2011) The high-resolution diffraction beamline p08 at petra iii. J Synchrotr Radiat 19:30-8

[24] Dawiec A, Garreau Y, Bisou J, Hustache S, Kanoute B, Picca F, Renaud G, Coati A (2016) Real-time control of the beam attenuation with XPAD hybrid pixel detector. J Instrum 11:P12018-P12018

[25] Yoneda Y (1963) Anomalous surface reflection of X rays. Phys Rev 131:2010-2013

[26] Renaud G, Garreau Y, Betinelli P, Tournieux A, Bisou J, Monteiro P, Elattaoui X (2013) Beamline fast and automatic attenuation system for X-ray detectors at Synchrotron Soleil. J Phys Confer Ser 425:8-12

[27] Parratt L (1954) Surface studies of solids by total reflection of X-rays. Phys Rev. https://doi.org/10.1103/PhysRev.95. 359

[28] Bauer E (1958) Phänomenologische Theorie der Kristallabscheidung an Oberflächen. I. Zeitschrift fur Kristallographie 110:372-394 
[29] Ohring M (1995) The materials science of thin films. In: Vacuum, vol 46. Academic Press, San Diego, Chap 7, p 85, 2nd ed

[30] Ohring M (1995) The materials science of thin films. In: Vacuum, vol 46. Academic Press, San Diego, Chap 5, p 85, 2nd ed

[31] Oura K, Lifshits V, Saranin A, Zotov A, Katayama M (2003) Surface science: an introduction. Advanced texts in physics. Springer, Berlin

[32] Franz G (2009) Low pressure plasmas and microstructuring technology. Springer, Berlin, Chap 4, pp 69-102

[33] Burle J, Fisher JM, Ganeva M, Pospelov G, Van Herck W, Wuttke J (2017) BornAgain: simulate and fit grazing incidence small-angle scattering.

[34] Vogel W (1998) X-ray diffraction from clusters. Cryst Res Technol 33
[35] Qiao L, Bi XF (2009) Microstructural orientation, strain state and diffusive phase transition of pure argon sputtered BaTiO3 film. J Phys D Appl Phys 42:175508

[36] David W, Shankland K, McCusker L, Bärlocher C (Eds) (2002) Structure determination from powder diffraction data. Oxford University Press. https://oxford.universitypressschol arship.com/view/10.1093/acprof:oso/9780199205530.001.0 001/acprof-9780199205530. Accessed 22 Sep 2020

[37] Fultz B, Howe JM (2007) Transmission electron microscopy and diffractometry of materials, 3rd Edn), p 58

[38] Rachwal JD (2010) X-ray diffraction applications in thin films and (100) silicon substrate stress analysis, Ph.D. thesis

Publisher's Note Springer Nature remains neutral with regard to jurisdictional claims in published maps and institutional affiliations. 